\title{
COMUNICAÇÃO
}

\section{ESTABELECIMENTO E MULTIPLICAÇÃO IN VITRO DE Physalis peruviana L.}

\author{
In Vitro establishment and multiplication of Physalis peruviana $\mathbf{L}$.
}

\author{
Anderson da Costa Chaves ${ }^{1}$, Márcia Wulff Schuch ${ }^{2}$, Alan Cristiano Erig ${ }^{1}$
}

\begin{abstract}
RESUMO
Visando o estabelecimento e a multiplicação in vitro de Physalis, foram realizados dois experimentos. Para o estabelecimento, testou-se 5 procedimentos de desinfestação das sementes (P1: Álcool 70\% durante 30 segundos; P2: Hipoclorito de Sódio 2,5\% durante 3 minutos; P3: Hipoclorito de Cálcio 2,5\% por 3 minutos; P4: Álcool 70\% por 30 segundos + Hipoclorito de Sódio 2,5\% por 3 minutos; P5: Álcool $70 \%$ por 30 segundos + Hipoclorito de Cálcio por 3 minutos). Metade das sementes foi mantida no escuro e a outra metade

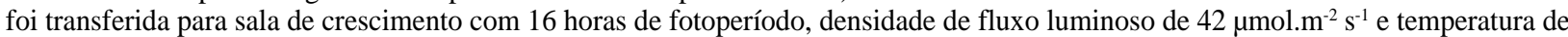
$25 \pm 2{ }^{\circ} \mathrm{C}$. Ao final dos 28 dias, o procedimento 3 mostrou as maiores taxas de contaminação in vitro. Sendo que as maiores porcentagens de germinação foram obtidas nos procedimentos de desinfestação 1, 2 e 4. Para a multiplicação foram avaliados os meios de cultura MS e MS $3 / 4$ (reduzido em $25 \%$ dos sais do meio inteiro), e as concentrações de: 0,$0 ; 0,1 ; 0,2$ ou $0,3 \mathrm{mg} \mathrm{L}^{-1}$ de BAP. Foram utilizados frascos com $30 \mathrm{~mL}$ de meio de cultura com o pH ajustado para 5,8 e ágar na concentração de $6 \mathrm{~g} \mathrm{~L}^{-1}$. Ao final de 21 dias, observou-se maior número de brotações na concentração de $0,3 \mathrm{mg} \mathrm{L}^{-1}$ de BAP para os dois meios de cultura estudados.
\end{abstract}

Termos para indexação: Pequenas frutas, Physalis, micropropagação, desinfestação.

\begin{abstract}
Aiming the in vitro establishment and the multiplication of Physalis peruviana L., two experiments were conducted. For the establishment it was tested five procedures of desinfestation of the seeds, (P1: alcohol $70 \%$ for 30 seconds; P2: sodium hypochlorite $2.5 \%$ for three minutes; P3: calcium hypochlorite $2.5 \%$ for three minutes; P4: alcohol $70 \%$ for 30 seconds + sodium hypochlorite $2.5 \%$ for three minutes; P5: alcohol $70 \%$ for 30 seconds + calcium hypochlorite for three minutes). Half of the seeds were maintained in the darkness and the other half were transferred for growth room with 16 hour- photoperiod, luminous flow density of $42 \mu \mathrm{mol}^{-2} \mathrm{~m}^{-2} \mathrm{~s}^{-1}$ and temperature of $25 \pm 2{ }^{\circ} \mathrm{C}$. After 28 days the procedure 3 showed the highest in vitro contamination rates. And the highest percentages of germination were obtained in the procedures of desinfestation 1,2 and 4. For the multiplication they were evaluated in the culture mediuns MS and MS $3 / 4$ (reduced in $25 \%$ of the salts of the full strenght), and the concentrations of $0 ; 0.1 ; 0.2$ and $0.3 \mathrm{mg} \mathrm{L}^{-1}$ of BAP. Flasks were used with $30 \mathrm{ml}$ of culture medium with the $\mathrm{pH}$ adjusted for 5.8 and with $6 \mathrm{~g} \mathrm{~L}^{-1}$ of agar. After 21 days larger shoots number was observed with $0.3 \mathrm{mg} \mathrm{L}^{-1}$ of BAP for the two culture mediuns studied.
\end{abstract}

Index terms: Small fruits, Physalis, Micropropagation, Desinfestation.

(Recebido para publicação em 21 de julho de 2004 e aprovado em 28 de julho de 2005)

Embora recente, a produção de pequenas frutas tem despertado a atenção de consumidores, processadores de frutas, agentes comercializadores e, por conseqüência, produtores em escala familiar e de médio e grande porte (HOFFMANN, 2003). Mais recentemente, a associação dessas frutas a propriedades nutracêuticas, tais como elevados teores de substâncias antioxidantes e anticancerígenas, aumentou a curiosidade do consumidor, em busca da suplementação alimentar a partir da diversificação da dieta com base em frutas. O termo "pequenas frutas" é utilizado para um grupo de espécies já consagradas em países tradicionais produtores, porém freqüentemente, novas espécies são inseridas neste conjunto, já que há flexibilidade nos conceitos que delimitam tais espécies componentes, havendo um grande campo a ser explorado para a inserção de espécies desconhecidas do mercado, tanto interno como externo, e que podem, em médio ou longo prazo, constituíremse em espécies de importância comercial (PAGOT \& HOFFMANN, 2003).

Uma espécie de grande valor nutricional e econômico que pode ser estudada para a incorporação no quadro das pequenas frutas é a Physalis peruviana L.. Esta frutífera caracteriza-se por produzir frutos açucarados e com bom conteúdo de vitamina A, C, ferro e fósforo (FISCHER \& ALMANZA, 1993). Segundo a Corporación Colombiana Internacional (1994), em diferentes regiões na Colômbia lhe atribuem propriedades medicinais, tais como a de purificar o sangue, diminuir a albumina nos rins, aliviar problemas de garganta e fortificar o nervo óptico.

\footnotetext{
${ }^{1}$ Engenheiro Agrônomo, Aluno do PPGA, Área de Concentração em Fruticultura de Clima Temperado, FAEM/UFPel - Campus Universitário - Cx. P. 354 96.010-900. - Pelotas, RS - chaves.ac@bol.com.br

${ }^{2}$ Engenheira Agrônoma, Dr ${ }^{\mathrm{a}}$, Professora Adjunta do Departamento de Fitotecnia - FAEM/UFPel - Pelotas, RS.
} 
Os principais métodos de obtenção de mudas destas espécies, envolvem sementes, estacas e micropropagação. Por meio da micropropagação é possível propagar espécies de difícil multiplicação, e ainda, obter mudas sadias, livres de vírus, bactérias e fungos, produzindo assim, um material de alta qualidade genéticosanitaria. No entanto, algumas limitações específicas limitam o uso extensivo do cultivo de tecidos vegetais in vitro. Um dos maiores entraves está na dificuldade de obter tecidos livres de contaminação, principalmente por bactérias, pois nem sempre se pode eliminá-las com o uso de antibióticos. O uso de diferentes agentes germicidas é fundamental para redução da contaminação dos explantes durante o estabelecimento in vitro. Os mais comuns são o etanol e os compostos à base de cloro, tais como hipoclorito de sódio e de cálcio (GRATTAPAGLIA \& MACHADO, 1998). Além disso, a concentração da solução desinfestante, a combinação dos princípios ativos e o tempo de exposição podem variar muito (MONTARROYOS, 2000), sendo necessária à adequação do protocolo de desinfestação de acordo com a espécie, cultivar e a sensibilidade do tecido a ser desinfestado.

Já na fase de multiplicação in vitro, o objetivo principal é produzir o maior número possível de plantas, no menor espaço de tempo, embora alguns aspectos importantes como qualidade e homogeneidade das partes aéreas produzidas devem ser considerados.

Dentre os pontos importantes na multiplicação in vitro, destacam-se aqueles referentes às concentrações de citocinina e o tipo de meio usado. Vários meios básicos têm sido utilizados na multiplicação de plantas, sendo o meio MS (MURASHIGE \& SKOOG, 1962) o mais empregado. A citocinina é indispensável nesta fase para a quebra da dominância apical e indução da proliferação de gemas axilares (HU \& WANG, 1983). Porém, o uso em excesso deste regulador é tóxico e caracteriza-se principalmente pela falta de alongamento das culturas, redução do tamanho das folhas, encurtamento dos entrenós, engrossamento exagerado dos caules, e vitrificação generalizada, ocasionando sérios problemas na fase de enraizamento (LANE, 1979; LESHEN et al., 1988).

Vislumbrando a possibilidade do cultivo da Physalis, obtendo-se uma nova alternativa para produtores de pequenas frutas da região, objetivou-se com este trabalho a adequação de protocolos para o estabelecimento e a indução de brotações in vitro.

Os experimentos foram realizados no Laboratório de Cultura de Células e Tecidos de Plantas, Departamento de Botânica, Instituto de Biologia da UFPel, RS.
Para o estabelecimento in vitro os tratamentos constituíram-se de 5 procedimentos de desinfestação das sementes: P1 - Álcool 70\% durante 30 segundos; P2 Hipoclorito de Sódio 2,5\% durante 3 minutos; P3 Hipoclorito de Cálcio 2,5\% por 3 minutos; P4 - Álcool 70\% por 30 segundos + Hipoclorito de Sódio 2,5\% por 3 minutos; P5 - Álcool 70\% por 30 segundos + Hipoclorito de Cálcio por 3 minutos. As sementes foram individualizadas em tubos de ensaio, com $10 \mathrm{~mL}$ de meio de cultura, sendo a metade destas mantidas no escuro e a outra metade transferidas para sala de crescimento com 16 horas de fotoperíodo, densidade de fluxo luminoso de $42 \mu \mathrm{mol} . \mathrm{m}^{-2} \mathrm{~s}^{-1} \mathrm{e}$ temperatura de $25 \pm 2{ }^{\circ} \mathrm{C}$. O meio de cultura empregado foi o $\mathrm{MS}^{3} / 4, \mathrm{pH} 5,8,30 \mathrm{~g} \mathrm{~L}^{-1}$ de sacarose e ágar na concentração de $6 \mathrm{~g} \mathrm{~L}^{-1}$. Foi avaliada a porcentagem de contaminação fúngica e bacteriana, e, aos 7, 14, 21 e 28 dias, a porcentagem de germinação.

Foi utilizado o delineamento experimental inteiramente ao acaso com 5 repetições por tratamento. Cada repetição foi constituída de 4 tubos de ensaio com uma semente. Os dados foram submetidos à análise da variância e as médias dos tratamentos comparadas estatisticamente pelo teste de Duncan, utilizando o programa Sanest (ZONTA \& MACHADO, 1984).

Para indução de brotações in vitro foram avaliados os meios de cultura MS e MS $3 / 4$ (reduzido em $25 \%$ dos sais do meio inteiro), e as concentrações de: 0,$0 ; 0,1 ; 0,2$ ou 0,3 $\mathrm{mg} \mathrm{L}^{-1}$ de BAP. Os explantes utilizados foram segmentos nodais com $1,0 \mathrm{~cm}$ de comprimento. Foram utilizados frascos com $30 \mathrm{~mL}$ de meio de cultura com o $\mathrm{pH}$ ajustado para 5,8 e ágar na concentração de $6 \mathrm{~g} \mathrm{~L}^{-1}$. Os explantes foram mantidos em sala de crescimento com 16 horas de fotoperíodo, densidade de fluxo luminoso de $42 \mu \mathrm{mol} \cdot \mathrm{m}^{-2} \mathrm{~s}^{-1}$ e temperatura de $25 \pm 2{ }^{\circ} \mathrm{C}$ Utilizou-se o delineamento experimental em blocos ao acaso, com 4 repetições por tratamento, sendo cada repetição constituída de um frasco contendo 5 explantes. Aos 35 dias de cultivo in vitro, foram avaliadas as variáveis, número médio de brotações, comprimento médio das brotações e número médio de gemas. Os dados foram submetidos à análise da variância e as médias dos tratamentos comparadas estatisticamente pelo teste de Duncan, utilizando o programa Sanest (ZONTA \& MACHADO, 1984).

Para a contaminação fúngica, avaliada ao final dos 28 dias de cultivo, foram observadas as maiores taxas de contaminação nas sementes tratadas com hipoclorito de cálcio, obtendo-se $55,22 \%$ de contaminação nas sementes mantidas na luz e $75 \%$ nas sementes mantidas no escuro. Já os demais tratamentos apresentaram taxas de contaminação

Ciênc. agrotec., Lavras, v. 29, n. 6, p. 1281-1287, nov./dez., 2005 
fúngica muito baixas não afetando o estabelecimento in vitro. Erig et al. (2003), utilizando vários procedimentos de desinfestação em segmentos nodais de Mirtilo (Vaccinium ashei Reade), também obteve maiores porcentagens de contaminação fúngica quando utilizou hipoclorito de cálcio como solução desinfestante.

Quanto à contaminação bacteriana, observou-se diferenças significativas nas respostas aos procedimentos utilizados na desinfestação, em que o tratamento com hipoclorito de cálcio possibilitou as maiores porcentagens de contaminação bacteriana, 34,54\%, quando as sementes foram mantidas na luz e $25 \%$ quando mantidas no escuro, sendo que os demais tratamentos possibilitaram taxas de contaminação praticamente nulas. Resultados semelhantes foram observados por Chaves et al. (2002), testando hipoclorito de sódio e de cálcio na desinfestação de explantes de Prunus cv. Mr. S 2/5, na qual registrou-se maiores taxas de contaminação bacteriana nos explantes tratados com hipoclorito de cálcio $(26,3 \%)$.

Conforme pode ser observado na Figura 1, para a variável porcentagem de germinação, o procedimento de desinfestação com hipoclorito de cálcio 2,5\% durante 3 minutos, promoveu a menor porcentagem de germinação $(10,83 \%)$. Esta baixa taxa de germinação deve-se, provavelmente, a maior porcentagem de contaminação fúngica e bacteriana resultantes deste procedimento de desinfestação.

Para os demais tratamentos (Figura 1), as maiores taxas de germinação foram observadas quando as sementes foram tratadas com álcool $70 \%$ por 30 segundos
+ hipoclorito de sódio $2,5 \%$ por 3 minutos $(22,90 \%)$, seguida de sementes tratadas com hipoclorito de sódio 2,5\% durante 3 minutos (21,78\%), álcool $70 \%$ durante 30 segundos (19,85\%) e álcool $70 \%$ por 30 segundos + hipoclorito de cálcio por 3 minutos $(14,30 \%)$. As baixas taxas de germinação para os cinco procedimentos de desinfestação podem estar relacionados com efeitos tóxicos dos agentes desinfestantes utilizados ou do tempo de exposição, pois testando diferentes substratos na germinação em casa-de-vegetação de Physalis peruviana L., Chaves et al. (2003) obtiveram 43,13\% e 30,26\% de germinação nos substratos solo e plantax, respectivamente.

De acordo com a análise da variância, houve diferença significativa para os fatores luminosidade e dias de germinação. O comportamento da germinação foi quadrático quando as sementes foram mantidas na luz, não apresentando germinação aos 7 dias, e atingindo o ponto de máximo (95,95\% de germinação), aos 28 dias de cultivo in vitro (Figura 2). Estes percentuais de germinação levam à confirmação do alto poder germinativo desta espécie se comparada com espécies florestais, como é o caso do Pau rosa (Aniba roseodora Ducke) e da Sucupira branca (Pterodon pubescens Benth), que não apresentam boa germinação in vitro ou levam período mais longo para germinar (COELHO, 1999; FRANÇA et al., 1997), respectivamente. Boas taxas de germinação também foram obtidas por Cordeiro et al. (2002) na germinação de sementes de Paricá (Schizolobium amazonicum Huber), na qual obtiveram $94 \%$ de germinação aos 15 dias de cultivo in vitro.

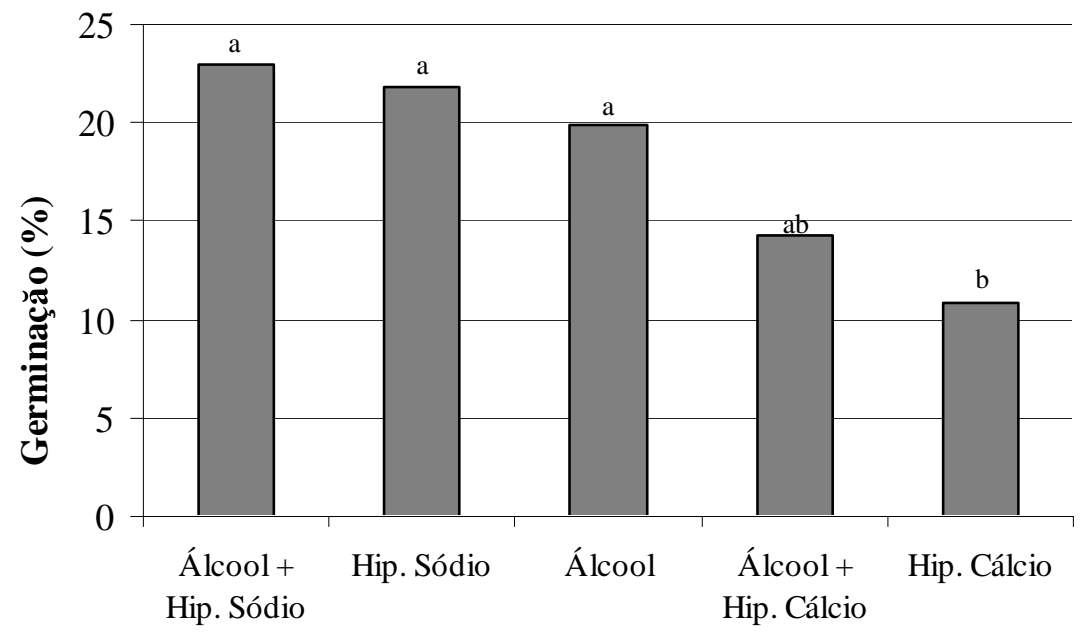

FIGURA 1 - Porcentagem de germinação para Physalis peruviana aos 28 dias de cultivo in vitro, utilizando cinco diferentes procedimentos de desinfestação de sementes. Valores seguidos por letras iguais, não diferem estatisticamente pelo teste de Duncam a 5\% de probabilidade. FAEM/UFPEL - Pelotas - RS. 2004. 
Neste trabalho, quando as sementes de Physalis foram mantidas no escuro, as taxas de germinação não foram influencidas pelos dias de cultivo in vitro, apresentando a taxa média de $0,31 \%$ de germinação em ambas datas de avaliação. Em virtude destes resultados devemos considerar esta espécie como fotoblástica positiva pois, segundo Evenari (1965), o elemento luz é essencial ao processo de classificação das espécies, designando a sensibilidade das sementes à luz como fotoblastismo positivo ou negativo.

Para a variável número médio de brotações, durante a multiplicação in vitro, houve diferenças significativas em função do meio de cultura e concentração de BAP. Para o meio de cultura MS o número médio de brotações apresentou um comportamento quadrático nas concentrações de BAP utilizadas; já no meio de cultura MS $3 / 4$, verificou-se um comportamento linear crescente para o número médio de brotações nas concentrações de BAP utilizadas, nas quais o número de brotações passou de 1 brotação por explante no tratamento testemunha, para 1,75 brotações na concentração de de $0,3 \mathrm{mg} \mathrm{L}^{-1}$ de BAP (Figura 3). Estes resultados estão de acordo com Rodrigues et al. (1999) que afirmam que meios baseados em formulações básicas diluídas têm possibilitado melhores resultados para multiplicação das mais diversas espécies. Segundo Preece (1995), a diminuição de sais e reguladores de crescimento nos meios de cultura é uma tendência mundial, e muitas pesquisas estão sendo realizadas com esta finalidade.

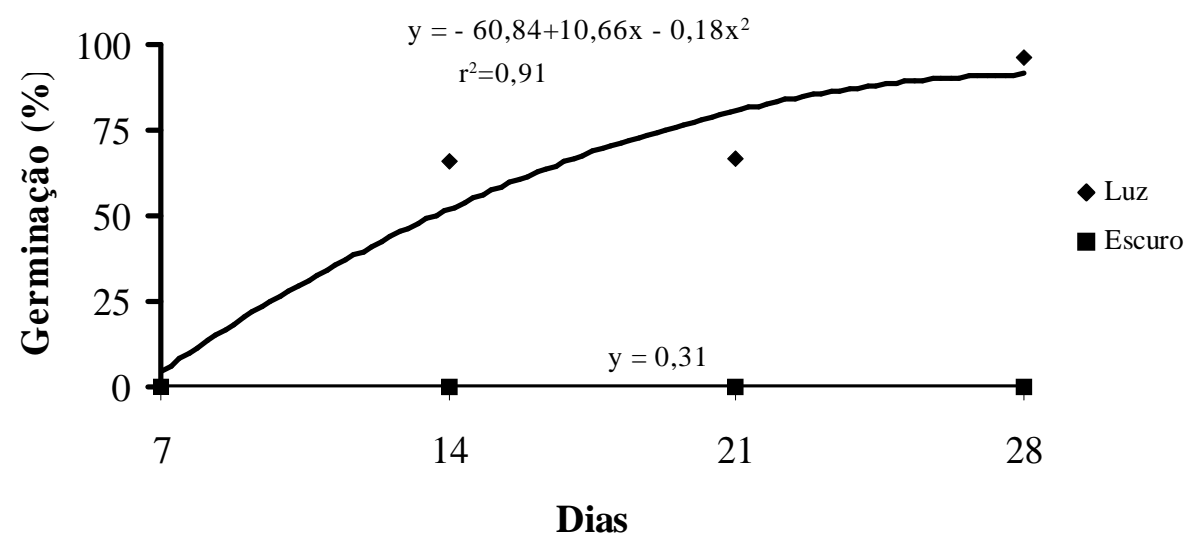

FIGURA 2 - Percentagem de germinação de Physalis peruviana mantidas em condições de luz e escuro aos 7; 14; 21 e 28 dias de cultivo in vitro. FAEM/UFPEL - Pelotas - RS. 2004.

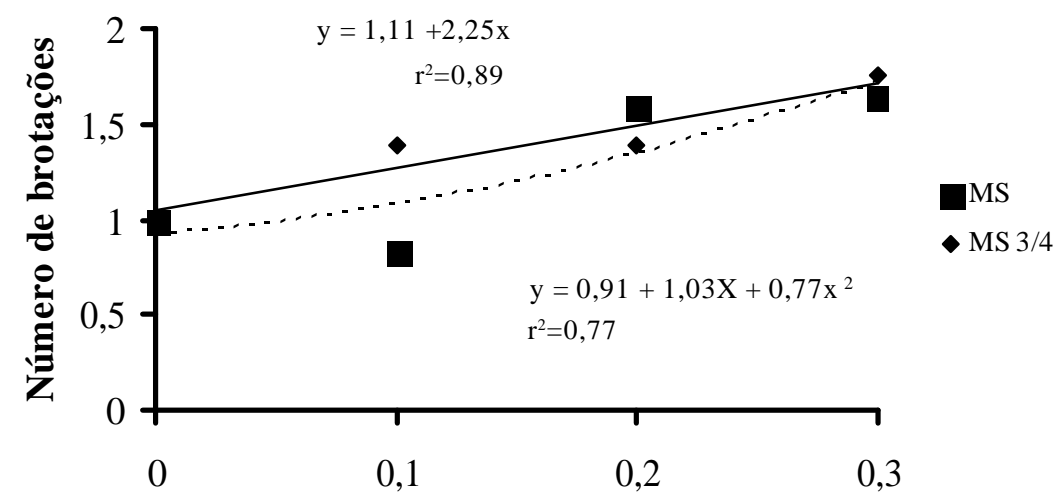

Concentração B AP $\left(\mathrm{mg} \mathrm{L}^{-1}\right)$

FIGURA 3 - Número médio de brotações de Physalis peruviana nos meios de cultura MS e $\mathrm{MS}^{3 / 4}$ em quatro concentrações distintas de BAP. FAEM/UFPEL - Pelotas - RS. 2004.

Ciênc. agrotec., Lavras, v. 29, n. 6, p. 1281-1287, nov./dez., 2005 
A variável comprimento da parte aérea (Figura 4), apresentou um comportamento quadrático, para as concentrações de BAP utilizadas, atingindo o ponto de máximo $(6,06 \mathrm{~cm})$ na ausência do regulador, e o ponto de mínimo $(1,73 \mathrm{~cm})$, na concentração de $0,3 \mathrm{mg} \mathrm{L}^{-1}$ de BAP. Bassan \& Bobrowski (2003), na multiplicação in vitro de Bryophyllum sp., observaram que os brotos produzidos em meio MS sem BAP apresentaram maior comprimento, que aqueles produzidos em presença de BAP, o que confirma as afirmações de Grattapaglia \& Machado (1998), que concentrações crescentes de citocininas inibem o alongamento das brotações.

Verificamos que, para esta espécie, concentrações elevadas de BAP aumentam a taxa de proliferação, no entanto, o tamanho das brotações tende a ser pequeno.

Para a variável número de gemas, houve um comportamento quadrático nas concentrações de BAP utilizadas, atingindo o ponto de máximo na concentração de $0,3 \mathrm{mg} \mathrm{L}^{-1}$ de BAP (7,69 gemas), e o ponto de mínimo na ausência deste regulador (5,42 gemas) (Figura 5). Chaves (2003), testando as concentrações de 0,$0 ; 0,3$ e $0,6 \mathrm{mg} \mathrm{L}^{-1}$ de BAP na multiplicação in vitro de Prunus, cultivares Okinawa e Mr. S 1/8, também obteve maior número de gemas na maior concentração testada. Verifica-se que estes resultados são devido ao encurtamento dos entrenós, proporcionado pelo aumento das concentrações de BAP. Segundo Leshen et al. (1988), este sintoma pode ser problemático, pois afeta o alongamento e torna-se um fator limitante na fase de enraizamento.

De acordo com os resultados obtidos, concluiu-se que a espécie Physalis peruviana L. apresentou um comportamento fotoblástico positivo no cultivo in vitro.

Os procedimentos de desinfestação álcool + hipoclorito de sódio, hipoclorito de sódio e álcool resultaram nas maiores taxas de germinação in vitro..

Na multiplicação in vitro, a concentração de $0,3 \mathrm{mg} \mathrm{L}^{-1}$ de BAP proporcionou o maior número de brotações e de gemas e o menor comprimento de brotações.

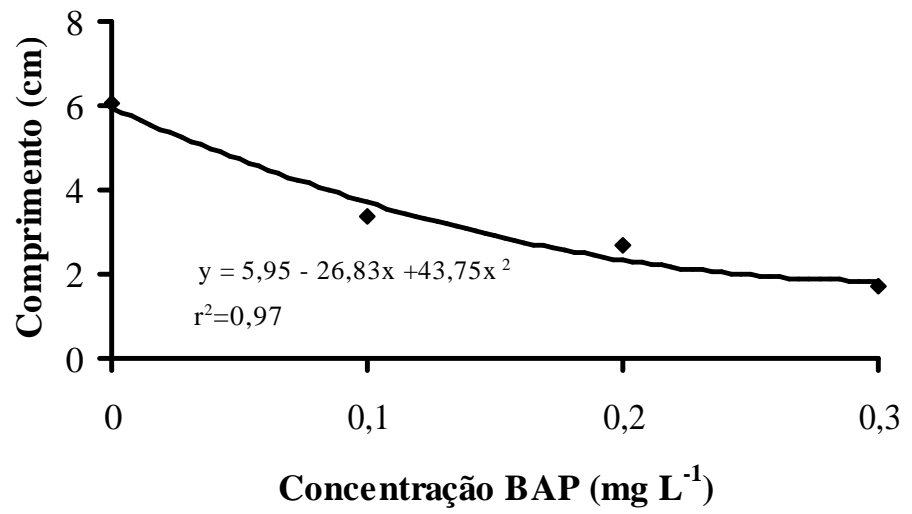

FIGURA 4 - Comprimento médio de brotações de Physalis peruviana em quatro concentrações distintas de BAP. FAEM/UFPEL - Pelotas - RS. 2004.

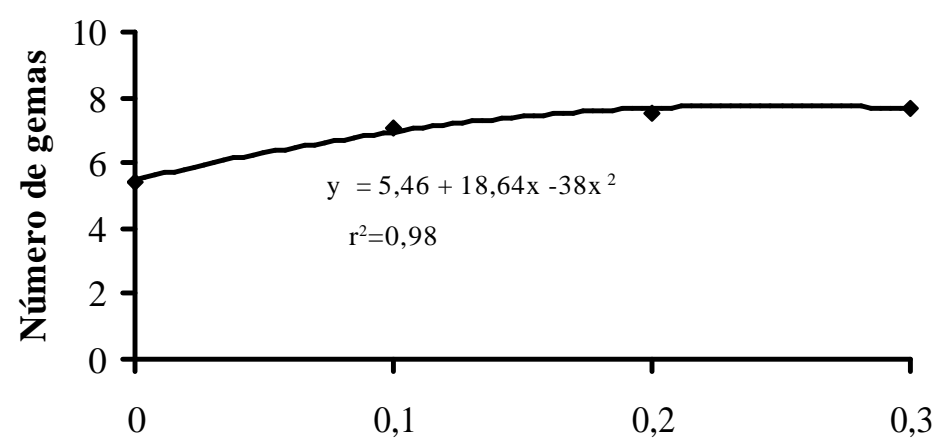

Concentração BAP (mg L $\left.\mathbf{~}^{-1}\right)$

FIGURA 5 - Número médio de gemas de Physalis peruviana em quatro concentrações distintas de BAP. FAEM/ UFPEL - Pelotas - RS. 2004. 


\section{REFERÊNCIAS BIBLIOGRÁFICAS}

BASSAN, J.; BOBROWSKI, V. L. Efeito de diferentes concentrações de BAP sobre a multiplicação in vitro de Bryophyllum sp. In: CONGRESSO BRASILEIRO DE FISIOLOGIA VEGETAL, 9., 2003, Atibaia, SP. Resumos... Atibaia: [s.n.], 2003. v. 15, p. 188.

CHAVES, A. da C.Micropropagação de porta-enxertos para fruteiras de caroço. 2003. 59 f. Dissertação (Mestrado em Fruticultura de Clima temperado) - Faculdade de Agronomia Eliseu Maciel, Universidade Federal de Pelotas, Pelotas, 2003.

CHAVES, A. da C.; ROCHA, P. S.; BIANCHI, V. J.; SCHUCH, M. W.; FACHINELLO, J. C. Desinfestação de explantes de prunus cv. Mr. S 2/5 no estabelecimento in vitro. In: CONGRESSO IBEROAMERICANO DE TECNOLOGIA POSTCOSECHA Y AGROEXPORTACIONES, 3.; CONGRESSO AGRONÔMICO DE CHILE, 53.; CONGRESSO DE LA SOCIEDAD CHILENA DE FRUTICULTURA, 3., 2002, Santiago. Resumos... Santiago: [s.n.], 2002. v. 72, p. 111.

CHAVES, A. da C.; SCHUCH, M. W.; PINHO, D. S. Avaliação do local e do substrato na germinação de sementes de Physalis peruviana L. In: CONGRESSO DE INICIAÇÃO CIENTÍFICA, 12.; ENPÓS, 5., 2003, Pelotas, RS. Resumos... Pelotas: [s.n.], 2003. CD-ROM.

COELHO, M. C. F. Germinação de sementes e propagação in vitro de sucupira branca (Pterodon pubescens (Benth.) Benth.). 1999. 119 p. Dissertação (Mestrado em Fitotecnia) - Universidade Federal de Lavras, Lavras, 1999.

CORDEIRO, M. C. C.; LAMEIRA, O. A.; LOPES, S. da C.; RIOS, M. S. Germinação in vitro de Paricá (Schizolobium amazonicum Huber). Biotecnologia Ciência \& Desenvolvimento, Brasília, n. 27, p. 58-62, jul./ago. 2002.

CORPORACIÓN COLOMBIA INTERNACIONAL. UNIVERSIDAD DE LOS ANDES Y DEPARTAMENTO DE PLANEACIÓN NACIONAL. Análisis internacional del sector hortofrutícola para Colombia. Bogotá: El Diseño, 1994. $165 \mathrm{p}$.

ERIG, A. C.; VICENZI, M.; CHAVES, A. C.; SCHUCH, M. W.; FACHINELLO, J. C. Desinfestação de explantes de Mirtilo (Vaccinium Aschei Reade) visando o estabelecimento de plantas in vitro. Revista Científica Rural, Bagé, v. 8, n. 1, p. 142-148, 2003.

EVENARI, M. Light and seed dormancy. In: RUHLAND, W. (Ed.). Encyclopedia of plant physiology. Berlim: SprigerVerlaag, 1965. v. 15, t. 2, p. 844-847.

FISCHER, G.; ALMANZA, P. J. Nuevas tecnologías en el cultivo de la uchuva Physalis peruviana L. Revista Agrodesarrollo, [S.1.], v. 4, n. 1-2, p. 294, 1993.

FRANÇA, R. B.; SANTOS, D. S. B.; MOTA, M. G. da C.; VIEIRA, I. M. da S.; CABRAL, B. L. R. Indução e crescimento de plântulas de pau-rosa (Aniba roseadora Ducke) in vitro. In: REUNIÃO DOS BOTÂNICOS DA AMAZONIA, 2., 1997, Salinópolis, Pará. Resumos... Salinópolis: [s.n.], 1997. p. 54.

GRATtAPAGlia, D.; MACHADO, M. A. Micropropagação. In: TORRES, A. C.; CALDAS, L. S. Cultura de tecidos e transformação genética de plantas. Brasília, DF: ABCTP/EMBRAPA/CNPH, 1998. p. 183-260.

HOFFMANN, A. Apresentação. In: SEMINÁRIO BRASILEIRO SOBRE PEQUENAS FRUTAS, 1., 2003, Bento Gonçalves. Anais... Bento Gonçalves: [s.n.], 2003. p. 6.

HU, C. Y.; WANG, P. J. Meristem, shoot tip and bud culture. In: EVANS, D. A.; SHARP, W. R.; AMMIRATO, P. V.; YAMADA, Y. (Eds.). Handbook of plant cell culture: techniques for propagation and breeding. New York: Macmillan, 1983. p. 117-227.

LANE, W. D. Regeneration of pear plants fron shoot meristem tips. Plant Science Letters, Limerick, v. 16, p. 183-260, 1979.

LESHEN, B.; WERKER, E.; SHALEV, D. P. The effect of cytokinins on vitrification in melon and carnation. Annals of Botany, London, v. 62, p. 271-276, 1988.

MONTARROYOS, A. V. V. Contaminação in vitro. ABCTP Notícias, Brasília, n. 36/37, p. 5-10, 2000.

MURASHIGE, T.; SKOOG, F. A revised medium for rapid growth and bioassays with tobacco tissue cultures. Physiologia Plantarum, Copenhagen, v. 15, p. 473-497, 1962. 
PAGOT, E.; HOFFMANN, A. Produção de pequenas frutas no Brasil. In: SEMINÁRIO BRASILEIRO SOBRE PEQUENAS FRUTAS, 1., 2003, Bento Gonçalves. Anais.. Bento Gonçalves: [s.n.], 2003. p. 9-14.

PREECE, J. E. Can nutrient salts partially substitute for plant growth regulators. Plant, Tissue Culture and Biotechnology, Rehovot, v. 1, n. 1, p. 26-37, 1995.
RODRIGUES, A. C.; FACHINELLO, J. C.; STRELOW, E.; FORTES, G. R. L. Estabelecimento in vitro de porta-enxertos de Prunus sp. Revista Brasileira de Fruticultura, Jaboticabal, v. 21, n. 2, p. 229-231, 1999.

ZONTA, E. P.; MACHADO, A. A. SANEST - Sistema de Análise Estatísticas para Microcomputadores. Pelotas: UFPel, 1984. 75 p. 